\title{
Estratégias e Ferramentas De Tradução No Universo Digital
}

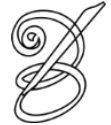 \\ Diogo N. Costa \\ (Doutorando - UFRJ) \\ diogoncosta@yahoo.com.br
}

Resumo: O presente trabalho visa expor as conclusões e reflexões provenientes da pesquisa realizada em âmbito de mestrado pelo presente autor. A pesquisa tem caráter exploratório e o intuito de determinar as possíveis ferramentas digitais on-line e off-line e suas formas de uso que podem auxiliar o tradutor durante o processo tradutório. Os dados para a análise foram gerados a partir de três grupos de informantes: tradutores inexperientes, tradutores estagiários e tradutores profissionais. A metodologia deste trabalho tem como base o conceito de triangulação, de forma que os dados foram obtidos a partir de aplicação de questionários e criação de protocolos verbais, tanto através da técnica de introspecção simultânea, quanto através da técnica de retrospeç̧ão imediata. Ao final da pesquisa foi possível determinar um paradigma para classificação das ferramentas tradutórias

Palavras-chave: Estudos da Tradução, Estratégias tradutórias, Tecnologia.

Abstract: This paper presents conclusions and reflections from the author's Master's research. The study was exploratory, with the purpose being to determine the possible online and offline digital tools and their forms of use that may help translators during the translation process. Data for the analysis were generated from three groups of informants: neophyte translators, trainee translators and professional translators. The methodology of this study was based on the triangulation concept. Data were obtained from questionnaires and the creation of verbal protocols from both simultaneous introspection and immediate retrospection. Results yielded a paradigm for classifying translation tools.

Keywords: Translation Studies, Translation Strategies, Technology.

\section{INTRODUÇÃO}

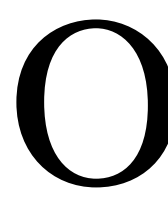

diálogo cada vez maior entre as nações, a especialização do conhecimento e o próprio sistema capitalista parecem gerar uma demanda cada vez maior de traduções, exigindo do tradutor seu máximo, que traduza o quanto puder o mais rápido possível e com qualidade.

A tecnologia para a tradução vem, então, com a finalidade de auxiliar (e pressionar) o profissional a atender essa expectativa. Temos hoje no mercado uma vasta gama de tradutores automáticos, programas de tradução assistidas, dicionários gerais e terminológicos, enciclopédias, fóruns, compartilhadores de textos, programas de mensagens instantâneas, redes de relacionamentos, ferramentas de buscas e até compartilhadores de vídeos que podem ser usados como ferramentas no auxílio da tradução. 
Algumas ferramentas são mais propícias a determinados problemas tradutórios, outras têm caráter mais amplo. Algumas ferramentas exigem maior "saber-como" operá-las que outras.

Cabe ao pesquisador, então, analisá-las, classificá-las e refletir sobre seus usos. Parece certo que não é possível um tradutor, inserido no mercado de tradução, não utilizar ferramentas digitais para realizar suas traduções, mas seria um absurdo aceitar que tais ferramentas tradutórias têm o poder de gerar traduções bem-sucedidas por si só.

Sobre tecnologia é importante lembrar que a internet, no auxílio do tradutor, ao mesmo tempo facilita o acesso aos dados, também sobrecarrega o usuário, aqui o tradutor, com esse excesso. Cabe, portanto, ao tradutor, ser capaz de, em meio ao grande número de dados e possibilidades, saber selecioná-los e transformá-los em informações e ferramentas que facilitem seu processo tradutório.

O presente trabalho pretende demonstrar, a partir de uma pesquisa realizada pelo presente autor ao longo de seu mestrado, como é possível classificar essas diversas ferramentas em duas grandes áreas e como problemas de mesma natureza são resolvidos,

170 geralmente, da mesma forma.

Sendo assim, o trabalho divide-se em alguns momentos: (1) serão explicitados a metodologia usada na pesquisa, a fonte de onde os dados foram retirados e nossos pressupostos teóricos; (2) demonstraremos algumas ferramentas tradutórias a partir de uma classificação possível; e (3) traçaremos uma linha que relacione a natureza do problema à estratégia utilizada e às ferramentas escolhidas. Dessa forma, comecemos abordando os alicerces da pesquisa.

\section{METODOLOGIA, CONCEITOS E SUJEITOS DA PESQUISA}

A metodologia do trabalho teve como base o conceito de "triangulação", que seria na sua origem: "um método geodésico e topográfico que permite determinar a localização de um ponto a partir de sua visualização de outros dois pontos, realizando a formação de um 'triângulo'" (SILVA, 2005, p. 31).

Ainda segundo Silva (ibidem), essa metáfora da triangulação é utilizada na área das Ciências Sociais quando múltiplos instrumentos de coleta e análise de dados dialogam entre si. Dessa forma, pretender-se-ia diminuir a possibilidade de dados artificiais gerados pelo próprio método de coleta de dados. 
Jakobsen (1999, p. 9; 2002, p. 193-194) chama a atenção para o fato de que essa metodologia permite um aperfeiçoamento da análise e, por consequência, torna a investigação mais abrangente e mais confiável. Sendo assim, a presente pesquisa contou com três instrumentos para coleta de dados: (1) questionários; (2) introspecção simultânea; e (3) retrospecção imediata.

Os questionários são justificados por seguirmos um paradigma interpretativista, ou seja, não se entende a verdade como algo único e nem se tem por objetivo a generalização dos dados; visa-se entender e interpretar os fenômenos dentro de um contexto. Sendo assim, os questionários foram aplicados para determinar as contingências sócio-histórico-culturais dos sujeitos de pesquisa, podendo, assim, chegar-se a conclusões sobre a realidade recortada.

Dentre as possibilidades dos métodos introspectivos, utilizou-se a técnica intitulada "falar alto", proposta por Ericsson e Simon (1987, p. 32-35), ou seja, durante o processo tradutório, o sujeito oralizou o que lhe veio à cabeça. Entretanto, é importante ressaltar que o elicitador, durante a realização da tradução, pôde questionar o informante sobre suas ações quando necessário para atingir os objetivos da pesquisa.

Apesar de concordar que há uma maior carga cognitiva quando o falante é obrigado a oralizar sua tradução, estamos de acordo com Cunha (2002, p. 69), quando a autora afirma que a introspecção é até o momento o que permite uma aproximação maior do que ocorre na mente do tradutor durante o momento da atividade tradutória. Sendo assim, não é possível abandonar as técnicas de introspecção quando realizamos uma pesquisa de caráter qualitativo, como é o caso da presente pesquisa.

E, uma vez que o objetivo do trabalho era observar as ferramentas tradutórias e suas formas de uso dentro de uma situação a mais próxima possível de uma situação real, optamos por não utilizar o software Translog, pois acreditamos que o programa não permitiria observar outros programas que poderiam ser usados pelo falante, como ferramentas TACs (Tradução Assistida por Computador) ou até mesmo funções utilizadas no Word pelos tradutores.

Sobre os sujeitos selecionados para a pesquisa, se faz importante dizer que eles foram agrupados em três grupos: o primeiro grupo foi composto por dois estudantes de Letras, nos últimos períodos da graduação em Português-Francês, e um estudante de mestrado, recémformado em Letras, habilitação Português-Francês, que nunca realizaram uma tradução profissionalmente. 
Esse primeiro grupo permitiu ao pesquisador observar como se dá, de forma intuitiva, o uso de ferramentas digitais para resolução de problemas de tradução ao longo do protocolo verbal.

O segundo grupo foi composto por dois tradutores, que chamamos aqui de "estagiários". Eles recebem esse nome devido ao fato de serem ou terem sido estagiários de uma empresa de tradução, concomitantemente à graduação de Letras nos últimos períodos da faculdade.

Nesse grupo, teríamos sujeitos que, acreditávamos, tinham experiência de tradução no mercado e já dominariam algumas ferramentas digitais para a realização de seu trabalho, ajudando ao pesquisador a investigá-las.

Esse grupo permitiu ao pesquisador observar o processo tradutório realizado por sujeitos que integravam o mercado atual de tradução, ainda que de forma inicial, e determinar o quão, para esses indivíduos, as ferramentas digitais faziam parte do seu cotidiano, além das possibilidades de uso dessas ferramentas. No último grupo de estudo temos dois tradutores profissionais. Ambos são professores de uma universidade federal.

172 Esse grupo permitiu estimar o quanto o universo digital está presente ou não na vida de tradutores profissionais, de que forma e quais são as motivações que os levam a utilizarem essas ferramentas.

É importante ressaltar que não conseguimos obter dados de profissionais que atuam exclusivamente como tradutores, apesar de um ano intenso de contato com amigos que se tornaram tradutores profissionais. Infelizmente, os tradutores não dispuseram de tempo para a realização da pesquisa, uma vez que o pesquisador precisaria estar presente durante o processo tradutório.

Essa recusa, entretanto, já revela uma característica do cotidiano do tradutor, principalmente do freelance: a sobrecarga de trabalho, pois, uma vez que o tradutor recebe por "produtividade", cada hora de trabalho é crucial para seu orçamento mensal.

Para a pesquisa utilizamos dois textos de natureza pragmática, ou seja, que tem por objetivo informar ao leitor fatos do cotidiano. Esses textos foram publicados no jornal $L e$ Monde. O primeiro foi usado para que houvesse uma fase de aquecimento, possibilitando que os sujeitos se habituassem ao processo de "falar alto".

O segundo, usado para geração dos dados, foi publicado no dia 11 de agosto de 2008, retirado da versão on-line do jornal (<www.lemonde.fr >), intitulado de "Les nageurs 
tricolores ne digèrent pas l'incroyable finale du 4x100m” (“Os nadadores tricolores não digerem a inacreditável final do 4x100m") e contido na seção "Sports" ("Esportes") do jornal.

O texto base foi escolhido por apresentar diversas estruturas que dependem, para serem compreendidas, de um conhecimento do universo cultural francês; além disso, durante o texto, há um jogo constante de palavras que remetem ao campo semântico da palavra água. Assim, se fez interessante observar na tradução as escolhas que permitiriam ou não manter esse jogo de palavras e como se deu o processo tradutório durante as alusões ao universo cultural francês. O texto era curto, com 455 palavras e quatro parágrafos.

O assunto tratado eram os Jogos Olímpicos de Pequim, mais precisamente sobre a derrota dos franceses pelos americanos por 8 milésimos, mesmo após terem liderado quase toda a prova de natação do revezamento 4x100 metros. Esperou-se que certas estruturas causassem problemas tradutórios, tanto na busca pelo equivalente do grupo nominal, quanto na adequação ao discurso jornalístico brasileiro.

É o caso de expressões como Baiser la gueule $\left(f^{*} d e^{*}\right)$, combler le retard (Recuperar o atraso), verre à moitié plein ("copo meio cheio") e On a fait avec ("fizemos o melhor"). Para essas fraseologias, os tradutores deveriam ter um conhecimento de mundo ou um "sabercomo" maior, pois a simples consulta ao dicionário não supriria essa carência.

Há ainda o uso, durante o texto, do ne, dito expletivo, que não forma uma negação simples (ne pas). E, ao indicarmos aos tradutores seu público-alvo (leitores do jornal $O$ Globo), previmos momentos em que seria necessário uma negociação entre o tradutor e o texto a partir de seu conhecimento discursivo-textual, como em Il nous a un peu baisé la gueule, que significa "ele nos $\mathrm{f}^{*} \mathrm{de}^{*}$ um pouco".

Seria a imagem que os tradutores possuíam do público-alvo condizente com o uso de palavrões? Caso a resposta fosse negativa, como resolver esse problema? Pretendeu-se analisar quais seriam as ferramentas, percursos e estratégias de tradução utilizadas por tradutores para resolução de seus problemas tradutórios durante o processo tradutório. Sendo assim, se faz importante ressaltar nossa noção de problema e estratégia.

De acordo com Faerch e Kasper (1983, p. 30-36), o problema seria uma insuficiência de conhecimento, momentânea ou não, que impede o sujeito de atingir determinado fim comunicativo. E, a partir dessa concepção, Corrêa e Neiva (2000, p. 36) afirmam ser possível observar um problema tradutório no momento em que ocorre uma interrupção do "fluxo tradutório". 
Entretanto, as autoras deixam claro que o problema tradutório não é apenas proveniente de uma insuficiência de conhecimento, mas também de uma insuficiência de meios para escolher a melhor opção para determinado segmento textual (ibidem).

Em relação à insuficiência de meios para resolver seus problemas, observamos duas possibilidades durante o uso de ferramentas tecnológicas para resolução dos problemas tradutórios, pois os sujeitos de pesquisas, ao se depararem com um problema tradutório, ou usavam uma ferramenta para solucioná-lo, ou usavam uma ferramenta de busca para encontrar uma ferramenta para solucioná-lo.

Em relação às estratégias tradutórias, Pagano afirma que:

Estabelecendo uma analogia com outras áreas da linguística aplicada, como ensino/aprendizagem de línguas estrangeiras, podemos dizer que, assim como existem estratégias de aprendizagem que o aprendiz bem-sucedido de línguas estrangeiras utiliza, também existem estratégias de tradução que o tradutor experiente utiliza para atingir suas metas e produzir um texto traduzido bem sucedido. (2000, p. 19-20)

Essa citação mostra que Pagano relaciona as estratégias às metas do tradutor que, ao atingir essas metas, alcançaria o "sucesso". Dessa forma, é possível entender que diferentes metas exigem do tradutor diferentes estratégias. Por esse motivo, antes de pedir ao tradutor para traduzir, se fez necessário definir os objetivos e algumas características, tais quais: prazo para entrega (a tradução poderia ser feita em quantos encontros se fizessem necessários), meio em que seria entregue (digital), lugar onde seria publicada a tradução (jornal $O$ Globo).

Segundo Pagano, o "aprendiz bem-sucedido" usaria estratégias de aprendizagem, enquanto o tradutor experiente usaria estratégias de tradução. Porém, acreditamos que tanto o "aprendiz malsucedido", quanto o "tradutor inexperiente" também utilizam estratégias; a diferença é que o tradutor "inexperiente" e o aprendiz "malsucedido" realizam estratégias não bem-sucedidas.

Sendo assim, o tradutor experiente é aquele que realiza a tradução através dos percursos menos tortuosos e atinge da melhor forma possível os objetivos preestabelecidos para a tradução. Ou seja, o tradutor experiente seria mais eficiente (utiliza menos "energia" para solucionar um problema tradutório) e mais eficaz (encontra uma solução satisfatória para o problema tradutório).

Em suma, tanto o tradutor experiente quanto o inexperiente selecionam as estratégias que consideram mais eficazes para alcançar os objetivos da tradução, e o quanto mais próximo dos seus objetivos o tradutor chegar com o menor esforço despendido, mais eficiente ele será. Lembramos que esses objetivos estão intimamente ligados, além dos objetivos 
pessoais do tradutor (seu projeto de tradução), ao contrato de fidelidade entre o autor, o texto e o público-alvo. Uma das diferenças entre o tradutor inexperiente e o experiente é o fato de que as estratégias dos tradutores experientes são mais eficazes e, por isso, há uma maior probabilidade de realizar uma tradução bem-sucedida (eficiente).

E, sobre as estratégias, a presente pesquisa chama a atenção para o fato de que existem tanto estratégias globais, quanto estratégias locais. Lörscher (1991, p. 96) diz que estratégias seriam "procedimentos utilizados pelos sujeitos para resolverem problemas de tradução". Ou seja, Lörscher se refere às estratégias locais.

Por outro lado, Jääskeläinen (1993, p. 116) afirma que estratégia é "um conjunto de regras ou princípios (vagamente formulados) que um tradutor utiliza para alcançar os objetivos determinados pela situação de tradução de maneira mais eficaz"; ou seja, a estratégia não está diretamente ligada ao problema, ou seja, ele se refere às estratégias globais. Tanto Jääskeläinen, quanto Lörscher não se opõem, entretanto, no presente trabalho, daremos conta apenas das estratégias locais de tradução. E, dito isso, vejamos, a partir dos dados obtidos, como seria possível classificar as ferramentas de tradução.

\section{AS FERRAMENTAS ESPECÍFICAS E POTENCIAIS DE TRADUÇÃO}

Ao longo da pesquisa identificamos dois tipos de ferramentas: (1) as Específicas (2) e as Potenciais. Consideramos ferramentas específicas de tradução toda e qualquer ferramenta que foi desenvolvida com o intuito de auxiliar o tradutor durante o processo tradutório. Sendo assim, duas delas seriam as mais óbvias: os softwares de "tradução assistida por computador" (TAC) e os tradutores automáticos.

Os TACs apresentam recursos variados: alinhamento, gestão de terminologia, controle de qualidade e capacidade de manipular formatos geralmente não editáveis através de processadores de textos comuns.

De forma sucinta, podemos dizer que os TACs são softwares que segmentam o texto em pequenas partes (frases ou períodos) visando facilitar o trabalho do tradutor. Cada segmento da tradução é salvo ao lado do TLO respectivo, facilitando a comparação entre ambos.

Esses segmentos são salvos em uma base de dados, que seria a memória de tradução. Assim, à medida que o tradutor vai utilizando o TAC, o programa vai criando uma base de dados cada vez mais extensa, que permitirá ao tradutor reutilizar essas estruturas, seja no mesmo texto, ou em textos diferentes. 
Alguns TACs permitem, ainda, realizar buscas de segmentos que não tenham uma similaridade $100 \%$ com o segmento a ser traduzido. Sendo assim, cabe ao tradutor ter bom senso, selecionando as passagens que podem ser traduzidas da mesma forma ou não.

Durante a pesquisa não pudemos observar o uso das ferramentas TACs, pois os tradutores selecionados não as tinham como parte de sua rotina. Cabe dizer, entretanto, que essas são ferramentas necessárias ao tradutor contemporâneo, principalmente por serem capazes de aumentar sua "produtividade".

Acreditamos que os tradutores escolhidos não as utilizavam por não terem na tradução seu principal sustento, uma vez que esses tradutores tinham outra profissão (professor) e suas traduções publicadas eram compostas, em sua maior parte, por obras literárias.

Devemos lembrar que no cotidiano do tradutor

O tradutor freelance, entretanto, muitas vezes é obrigado a usar uma ferramenta TAC, não só pela questão da produtividade, mas também pela imposição da editora, que determina, inclusive, a ferramenta TAC que deverá ser usada para a tradução.

Em relação aos tradutores automáticos, temos o Google Tradutor, que é hoje o de 176 maior repercussão midiática. Por estar acoplado ao site de busca mais utilizado no momento, opera com uma enorme base de dados, sendo capaz de comparar diversas páginas indexadas no Google com o intuito de expandir e atualizar seu banco de dados.

Segundo uma reportagem publicada na revista Veja, intitulada "A língua do Google", de 2006 para 2010, o Google passou a traduzir de 3 para 52 idiomas e pretende chegar a pelo menos 250 idiomas em 2020.

Já as ferramentas potenciais de tradução seriam ferramentas que não foram desenhadas com fins tradutórios, mas que podem ser usadas como tais. Através do Google, ferramenta de busca, o tradutor pode buscar dicionários especializados, além de sites sobre determinado assunto, utilizando-o para atualizar seu conhecimento de mundo.

O Google Web permite realizar uma busca paradigmática, ou seja, ver o uso de um determinado sintagma em diferentes contextos e, a partir do paradigma apresentado, encontrar o melhor equivalente para o texto de chegada, permitindo a criação e comparação de corpus.

O Google Imagem permite ao tradutor buscar o referente ao qual o signo remete.

O Youtube é um compartilhador de vídeos que permite ao tradutor, por vezes, vivenciar a situação narrada no texto de origem, principalmente no caso de textos pragmáticos. 
O Wikipédia digital multilíngue é uma enciclopédia aberta que qualquer pessoa pode editar, o que exige muito cuidado por parte do leitor. Mas por ser multilíngue, o tradutor pode buscar o assunto em francês, por exemplo, e logo em seguida, na opção de idiomas (canto esquerdo inferior), pode pedir uma versão do artigo em português. $O$ tradutor não encontrará uma tradução, mas sim um texto sobre o mesmo assunto na língua desejada. Podendo ajudar o tradutor a definir qual é o equivalente do sintagma a ser traduzido, uma vez que textos sobre os mesmos assuntos abordarão, possivelmente, os mesmos campos semânticos.

O Wordreference é uma ferramenta que, além de dicionário, tem a opção fórum, na qual o tradutor pode fazer consultas a nativos ou a especialistas sobre o assunto pesquisado. Assim, através de uma construção coletiva do conhecimento, o tradutor pode chegar às suas conclusões.

Outro fator interessante é que esse site gera uma memória, ou seja, um tradutor que busca o mesmo assunto pode verificar a discussão e reiniciá-la, caso não concorde com a conclusão alcançada anteriormente, ou determinar a solução do seu problema.

Além disso, há uma extensa gama de dicionários on-line:

- Trésor de la langue française - dicionário on-line monolíngue de francês com 100.000 palavras e suas histórias, 270.000 definições, e 430.000 exemplos;

- IATI (InterActive Terminology for Europe) - dicionário especializado multilíngue possui termos técnicos em diversas áreas de conhecimento: educação, direito, economia, entre muitas outras.

Há ainda sites, dependendo do par linguístico a ser traduzido, que podem ajudar o tradutor a fazer uma análise de corpus, como o Linguatools, para o par linguístico alemão e outros idiomas; e o Mymemory, com diversos idiomas disponíveis. Esses sites são, na verdade, "bancos de dados" bidirecionais capazes de buscar "possíveis" traduções na língua escolhida para um determinado sintagma.

O Compara é um site de banco de dados para o par inglês-português. E, há, ainda, bancos de dados monolíngues, como o WebCorp e o British National Corpus, ambos de língua inglesa, o primeiro na versão americana e o segundo na versão britânica.

Vejamos, finalmente, a relação observada entre problemas, estratégias e percursos realizados na internet. 


\section{PROBLEMAS, ESTRATÉGIAS E PERCURSOS REALIZADOS}

A partir da pesquisa bibliográfica realizada com base nas obras de Cunha (2002), Kleiman (1989), Coste (1978; 1988) e Moirand (1982), concluímos que existem problemas tradutórios de três naturezas distintas: (1) linguísticos, (2) discursivo-textuais e (3) de conhecimento de mundo.

Consideramos que problemas linguísticos são os que envolvem a insuficiência de conhecimento em relação à apropriação de modelos fonéticos, lexicais e gramaticais do sistema da língua. Observamos que esses problemas são resolvidos por meio de dicionários, enciclopédias e fóruns, catalogados durante a pesquisa da seguinte forma:

1 - Dicionário monolíngue na memória do computador (Francês).

2 - Dicionário monolíngue na memória do computador (Português)

3 - Dicionário monolíngue on-line (Francês)

4 - Dicionário bilíngue na memória do computador

5 - Dicionário bilíngue on-line

6 - Google utilizado como dicionário

7 - Google como buscador de páginas

8 - Google para criação de corpus

9 - Wikipédia e enciclopédias

10 - Fóruns

Esses resultados foram extraídos da tabela a seguir, que apresenta o número total de problemas linguísticos de cada sujeito e a forma como esses problemas foram resolvidos através das ferramentas digitais. TI significa tradutor iniciante, TE significa tradutor estagiário e TP significa tradutor profissional, sendo essas abreviaturas válidas para todas as tabelas deste artigo: 


\begin{tabular}{|c|c|c|c|c|c|c|c|c|}
\hline \multirow{12}{*}{$\begin{array}{l}\text { Problema } \\
\text { linguístico } \\
\text { resolvido } \\
\text { através de }\end{array}$} & & \multicolumn{7}{|c|}{ TRADUTORES } \\
\hline & & TI1 & TI2 & TI3 & TE1 & TE2 & TP1 & TP2 \\
\hline & $\begin{array}{c}\text { Dicionário monolíngue na } \\
\text { memória do computador } \\
\text { (Francês) }\end{array}$ & 7 & & & & 3 & 5 & \\
\hline & $\begin{array}{c}\text { Dicionário monolíngue na } \\
\text { memória do computador } \\
\text { (Português) }\end{array}$ & 4 & & & & & 1 & 1 \\
\hline & $\begin{array}{l}\text { Dicionário monolíngue on- } \\
\text { line (Francês) }\end{array}$ & & & 21 & & & & \\
\hline & $\begin{array}{l}\text { Dicionário bilíngue na } \\
\text { memória do computador }\end{array}$ & & 6 & & & 18 & & \\
\hline & Dicionário bilíngue on-line & & & & 16 & & & \\
\hline & Google como dicionário & & & 1 & & & & \\
\hline & $\begin{array}{c}\text { Google como buscador de } \\
\text { páginas }\end{array}$ & & & 1 & 1 & & 1 & \\
\hline & $\begin{array}{c}\text { Google para criação de } \\
\text { corpus }\end{array}$ & & & & 1 & 2 & & \\
\hline & Wikipédia e enciclopédias & & & 1 & 1 & & & \\
\hline & Fóruns & & & & 2 & & & \\
\hline & $\begin{array}{l}\text { Total de problemas de } \\
\text { natureza linguística }\end{array}$ & 11 & 6 & 24 & 21 & 23 & 7 & 1 \\
\hline
\end{tabular}

Quadro 1 - Total de problemas de natureza linguística observados e como foram resolvidos

Os problemas de natureza discursivo-textual foram considerados como a união da definição de componentes discursivos de Moirand (1982, p. 20), relativa ao conhecimento e apropriação de diferentes tipos de discursos e a sua organização em função da situação de comunicação da qual sua produção/interpretação fazem parte, e as definições de componente textual de Kleiman (1989, p. 13) e Coste (1978, p. 15-16), relativas aos conjuntos de noções e conceitos que o leitor possui sobre o texto, envolvendo os reconhecimentos dos tipos de textos e as formas de discursos. Englobados pela nomenclatura "discursivo-textual".

Em relação a esse tipo de problema, o que se observou foi que os tradutores, a princípio, utilizam buscas internas para resolvê-los, possivelmente devido ao fato de a natureza do texto em questão (jornalístico) ser bem recorrente no cotidiano de todos os tradutores observados. Entretanto, para resolver problemas por meio de busca externa, os tradutores usaram o Google como ferramenta para criação de corpora: 


\begin{tabular}{|c|c|c|c|c|c|c|c|c|}
\hline & & \multicolumn{7}{|c|}{ TRADUTORES } \\
\hline & & TI1 & TI2 & TI3 & TE1 & TE2 & TP1 & TP2 \\
\hline \multirow{3}{*}{$\begin{array}{c}\text { Problema } \\
\text { discursivo-textual } \\
\text { resolvido através } \\
\text { de }\end{array}$} & Busca interna & 3 & & 1 & & & 1 & \\
\hline & $\begin{array}{c}\text { Google para } \\
\text { criação de } \\
\text { corpus }\end{array}$ & & & & & 1 & 1 & \\
\hline & TOTAL & 3 & & 1 & & 1 & 2 & \\
\hline
\end{tabular}

Quadro 2 - Total de problemas de natureza discursivo-textual observados e como foram resolvidos

E, finalmente, os problemas de natureza de conhecimento de mundo surgem quando há uma ausência relacionada aos conhecimentos prévios de mundo que os sujeitos deveriam ter para compreensão do texto traduzido, assim como as regras sociais e as normas de interação entre os indivíduos e as instituições permeadas no texto.

Observamos que, no universo digital, eles são resolvidos através de um site buscador. Vejamos abaixo a tabela que demonstra os dados obtidos:

\begin{tabular}{|c|c|c|c|c|c|c|c|c|}
\hline \multicolumn{2}{|c|}{} & \multicolumn{7}{|c|}{ TRADUTORES } \\
\hline \multirow{2}{*}{$\begin{array}{c}\text { Problema de } \\
\text { conhecimento de } \\
\text { mundo resolvido } \\
\text { através de }\end{array}$} & TI1 & TI2 & TI3 & TE1 & TE2 & TP1 & TP2 \\
\cline { 2 - 9 } & $\begin{array}{c}\text { Solução de } \\
\text { abandono }\end{array}$ & & 1 & & & & & \\
\cline { 2 - 10 } & $\begin{array}{c}\text { Google como } \\
\text { site de busca }\end{array}$ & & & 1 & 2 & & 1 & 1 \\
\cline { 2 - 10 } & Busca no TLO & 1 & & & & & & \\
\hline & TOTAL & 2 & 1 & 1 & 1 & & 1 & 1 \\
\hline
\end{tabular}

Quadro 3 - Total de problemas de natureza de conhecimento de mundo observados e como foram resolvidos

Cabem, então, algumas conclusões.

\section{CONCLUSÕES}

Observamos, ao longo da pesquisa, como a Web de fato auxilia o tradutor durante o seu processo tradutório por meio de uma vasta gama de possibilidades de ferramentas. Entretanto, durante os protocolos e os questionários realizados, observamos, também, que a única justificativa para um tradutor escolher usar uma ferramenta em detrimento de outra seria 
sua identificação pessoal para com a ferramenta e, obviamente, sua habilidade em manipulála.

Sendo assim, um curso que vise ensinar o aluno a traduzir deve incluir um módulo que permita aos alunos apreenderem as diversas possibilidades de ferramentas digitais e refletirem sobre os usos dessas ferramentas.

Ao compararmos a pesquisa realizada com pesquisas anteriores que utilizavam também protocolos verbais para a identificação de problemas tradutórios: Cunha 2002, Santos 2002, Silva 2005, percebemos que as estratégias de busca de subsídios externos não foram modificadas com o advento dos mecanismos digitais. O que ocorre, na verdade, é uma maior facilidade de acesso a essas fontes de buscas externas: dicionários e enciclopédias, textos paralelos e especialistas.

O que também chama a atenção em relação ao manuseio das ferramentas digitais é a necessidade de criatividade por parte do tradutor, pois algumas ferramentas tiveram desvios de sua função original, como o uso de um site de busca para a criação de corpus ou consulta a uma enciclopédia Wiki para encontrar textos paralelos do TLO no TLT.

As ferramentas digitais se apresentam, de fato, como uma poderosa fonte de busca de subsídios externos, exigindo do tradutor um "saber-como" manuseá-las. Entretanto, pudemos verificar que tais ferramentas não foram capazes de garantir, por si só, traduções bemsucedidas por parte do tradutor iniciante.

Acreditamos, contudo, que, caso o tradutor iniciante tenha consciência do duplo ato comunicativo no qual a tradução está inserida, assumindo ao longo do processo tradutório seu papel discursivo dentro desses atos de linguagem, mesmo que ele ainda não tenha ampla proficiência no TLO e no TLT, ele terá maior possibilidade de realizar uma tradução bemsucedida caso domine as ferramentas digitais.

Pois, as ferramentas digitais agilizam e amplificam as possibilidades de aquisição de uma informação, ainda que ele (o tradutor iniciante) precise efetuar percursos mais longos que o tradutor profissional. 


\section{REFERÊNCIAS BIBLIOGRÁFICAS}

CORRÊA, Angela Maria da Silva; NEIVA, Aurora Maria Soares. Estratégias e problemas do tradutor aprendiz: uma visão introspectiva do processo tradutório. In: MONTEIRO, Maria José (Org.). Práticas discursivas: instituição, tradução e literatura, UFRJ, Rio de Janeiro, 2000. p.34-52.

COSTE, Daniel. Leitura e competência comunicativa. In: GALVES, C., ORLANDI, E., OTTONI, P. O Texto: escrita e leitura. Campinas: Pontes, 1988.

CUNHA, Tânia Reis. Fatores discursivos de interrupção do fluxo tradutório do francês para o português. 2002. 230 f. Tese (Doutorado) - UFRJ, Rio de Janeiro. 2002.

ERICSSON, K. A.; SIMON, H. A. Verbal reports on thinking. In: FAERCH, C.; KASPER, G. Introspection in second language research. Multilingual Matters Ltd: Clevedon, Philadelphia, 1987. p. 24-53.

FAERCH, C.; KASPER, G. On identifying communication strategies in interlanguage production. In: FAERH, C.; KASPER, G. (Ed.). Strategies in interlanguage communication. London: Longman, 1983.

JÄÄSKELÄINEN, Riitta (1993). Investigating Translation Strategies. In: TIRKKONENCONDIT,Sonja; LAFFLING, John (eds). Recent Trends in Empirical Translation Research. Studies in Languages n 28. Joensuu: University of Joensuu. p. 99-120

182 JAKOBSEN, A.L. Logging target text production with Translog. In HANSEN, G (Ed.). Empirical translation studies: process and product, (Copenhagen Studies in Language Series 27). Copenhagen: Samfundslitteratur. 2002. p. 9-20.

Orientation, segmentation, and revision in translation. In HANSEN, G (Ed.). Empirical translation studies: process and product, (Copenhagen Studies in Language Series 27). Copenhagen: Samfundslitteratur. 2002. p. 191-204.

KLEIMAN, Angela. Texto e leitor: aspectos cognitivos da leitura. Campina, SP: Pontes, 1989. 82p.

LÖRSCHER, Wolfgang. Translation Performance, Translation Process, and Translation Strategies: A Psycholinguistic Investigation. Tübingen: Gunter Narr, 1991.

MOIRAND, Sophie. Enseigner à communiquer en langue étrangère. Paris: Hachette, 1982. $188 \mathrm{p}$.

PAGANO, Adriana; MAGAlHÃES, Célia; ALVES, Fábio. Traduzir com autonomia: estratégias para o tradutor em formação. São Paulo: Contexto, 2000.

PAVÃO JUNIOR, Jadyr. A língua do Google. Veja, São Paulo, n. , p.122-131, 05 abr. 2010. Semanal. Disponível em: <http://clippings-artigos.blogspot.com/2010/05/lingua-dogoogle.html>. Acesso em: 18 maio 2010.

SANTOS, Luiz Américo Portela dos. O processo tradutório: análise de problemas e estratégias de solução em tradução do francês para o português. Dissertação (mestrado). Letras Neolatinas. Rio de Janeiro: Faculdade de Letras, UFRJ, 2002.

SILVA, Lucília Marques Ferreira da. Pesquisa auto-etnográfica do processo tradutório desenvolvido de metodologia e análise do uso de buscas externas. Dissertação (mestrado) Letras Neolatinas. Rio de Janeiro: Faculdade de Letras, UFRJ, 2005. 